\title{
A POLÍCIA MILITAR NA SEGURANÇA PÚBLICA DO ESTADO DEMOCRÁTICO DE DIREITO BRASILEIRO
}

\author{
Marcus Pinto Aguiar ${ }^{1}$ \\ Everaldo Ferreira Santana ${ }^{2}$
}

\section{RESUMO}

O trabalho objetiva analisar aspectos da Polícia Militar brasileira sob a perspectiva da segurança pública no Estado Democrático de Direito, considerando o previsto na Constituição Federal de 1988. Utiliza-se abordagem histórica do perfil da Polícia Militar, da ditadura militar à redemocratização do Brasil, além da pesquisa bibliográfica. Conclui-se que há dificuldades de superação da visão de combate ao inimigo (interno) - própria da Polícia Militar em Estado de Exceção - para uma perspectiva de serviço à comunidade, no contexto atual democrático pautado pela promoção de direitos fundamentais, sendo necessária uma formação no sentido de compreender seu novo papel.

Palavras-chaves: Polícia Militar; Segurança Pública; Estado Democrático de Direito; Direitos Fundamentais.

\section{THE MILITARY POLICE IN THE PUBLIC SECURITY OF THE BRAZILIAN DEMOCRATIC STATE OF LAW}

\begin{abstract}
The paper aims to analyze aspects of the Brazilian Military Police from the perspective of public security in the Democratic State of Law, considering the Federal Constitution of 1988. By the historical approach of the Military Police profile, from the military dictatorship to the redemocratization and the bibliographic research, it concludes that there are difficulties of overcoming the vision of combat to the enemy (internal) for a perspective of service to the community, in the current democratic context guided by the promotion of fundamental rights, being necessary a formation in the sense of understanding his new role.
\end{abstract}

Keywords: Public Security; Democratic State of Law; Military Police; Fundamental Rights.

\footnotetext{
${ }^{1}$ Doutor e Mestre em Direito Constitucional Público e Teoria Política, na linha de pesquisa em Direitos Humanos, pela Universidade de Fortaleza (CE); ex-bolsista PROSUP/CAPES; Doutor em Ciências Jurídicas e Sociais pela Universidad del Museo Social Argentino,(cuida-se de Universidade localizada em Buenos Aires, Argentina); Pós-graduado em Direito do Trabalho e Direito Civil; Especialista em Administração de Empresas pela Universidade Estadual do Ceará (UECE); Graduado em Direito e Engenharia Mecânica pela Universidade Federal do Ceará; Membro do Grupo de Estudos e Pesquisas em Direitos Culturais da Universidade de Fortaleza; Coordenador do Grupo de Estudos e Pesquisas Tribunal Multiportas e Gestão de Conflitos, do Centro Universitário INTA - UNINTA; Membro da Comissão Especial de Mediação, Conciliação e Arbitragem da $\mathrm{OAB} / \mathrm{CE}$; membro-fundador do Instituto Brasileiro de Direitos Culturais (IBDCult) e Presidente na gestão de 2014-2017; Membro do Conselho Fiscal do IBDCult; Mediador e Conciliador Judicial formado pelo NUPEMEC do TJ/CE; Docente credenciado da Escola Superior da Magistratura do Estado do Ceará - ESMEC; parecerista de revistas acadêmicas. Docente do curso de graduação em Direito do Centro Universitário INTA - UNINTA.

${ }^{2}$ Mestre em Direito Constitucional pela Universidade de Fortaleza - UNIFOR (2011), Bacharel em Segurança Pública pela Universidade Estadual do Maranhão (1996) e em Direito pelo Centro Universitário do Maranhão (2008).
} 


\section{INTRODUÇÃ̃O}

Com o fim do regime ditatorial-militar brasileiro e o início do processo de democratização, especialmente por meio da promulgação da Constituição Federal de 1988, os representantes do povo brasileiro - em Assembleia Nacional Constituinte - buscaram instituir um Estado Democrático de Direito, destinado a assegurar alguns valores elencados como de máxima importância - supremos - para a sociedade brasileira, entre eles: a segurança e o exercício dos direitos sociais e individuais.

No entanto, a efetivação do compromisso expresso no Preâmbulo constitucional, em que pese o Supremo Tribunal Federal já ter se manifestado no sentido de que ele não tem força normativa, e muito menos vinculativa, dá-se plenamente com a apreensão de tais valores pelos poderes públicos, como diretrizes para suas condutas e como instrumento de interpretação e integração das normas constitucionais, garantindo de forma incondicional os direitos fundamentais a todos.

É oportuno ressaltar que de nada adiantaria o tecnicismo lógico-formal, próprio da expressão de tais direitos fundamentais, se não se lhes fizesse corresponder um conjunto de garantias, concomitantemente outorgadas com a finalidade de tutelá-los, por meio de instrumentos adequados e hábeis tanto à sua efetivação, quanto à sua promoção contínua.

O Estado se apresenta como ente garantidor da segurança da sociedade e, para tanto, utiliza-se de vários mecanismos, dentre eles o seu poder de polícia, exercido mediante força legal, submetendo a vontade privada à pública; de modo que, dentre as atribuições do Estado brasileiro frente à sociedade, destaca-se a segurança pública, que, constitucionalmente, foi disposta como dever, sendo considerada também "direito e responsabilidade de todos", com o propósito de promover "a preservação da ordem pública e da incolumidade das pessoas e do patrimônio" mediante exercício das polícias e do corpo de bombeiro militar.

Ao definir tais atribuições, o constituinte originário inseriu a Polícia Militar como instituição que realiza atividades no intuito de proteger a sociedade, restando à previsão operacional de como se dá a adequação à nova realidade - na ordem democrática - dessa instituição que acabara de sair de um regime de exceção, no qual atuava exatamente na restrição dos direitos, e que, agora, por conta da ordem política e jurídica fundada pela Constituição de 1988, deve respeitar e promover direitos fundamentais individuais e coletivos. 
Nesse contexto, entende-se a justificativa da pesquisa ao se levar em consideração que o tratamento democrático da segurança pública e da atuação dos agentes policiais, inclina-se a um relacionamento social pautado acima de tudo por relações cordiais e pacíficas entre seus membros, típico de sociedades democráticas nas quais todos reconhecem seu próprio valor e o dos demais.

A partir desse entendimento, o estudo procura avaliar os acontecimentos decorrentes da atuação das polícias militares no Brasil e que, insistentemente, afetam a sociedade de forma diferenciada, promovendo, inclusive, ocorrências cujo desrespeito aos direitos humanos fundamentais têm sido constante.

O desenvolvimento do tema é embasado na análise dos princípios do Estado Democrático de Direito, demonstrando a importância de um conceito de segurança pública que permita maior participação social e respeito aos direitos fundamentais da parte das polícias militares; outrora, principal carência de uma política de segurança pública em um contexto de um governo totalitário. Além disso, procura também identificar as necessidades de adequação à realidade democrática brasileira, no que tange aos serviços de segurança pública.

O presente trabalho adotou a metodologia de pesquisa bibliográfica, principalmente em matérias relativas ao direito constitucional, à segurança pública e os direitos humanos fundamentais, pautando-se ainda na comparação histórica acerca da Polícia Militar e de suas atribuições no período de transição da ditadura militar brasileira para o processo de democratização, incluindo a atualidade de suas atividades.

Assim, em virtude da importância da segurança pública, uma análise da atuação da polícia militar junto a uma sociedade democrática se faz necessária, visto que uma melhor atuação dessas instituições proporciona maior proximidade dos preceitos constitucionais delineadores do verdadeiro Estado Democrático de Direito.

\section{O ESTADO DEMOCRÁTICO DE DIREITO E A SEGURANÇA PÚBLICA}

A palavra democracia tornou-se, no decurso da história, facilmente utilizada nos fundamentos de institucionalização de diversos modelos de Estado que se apresentam no mundo moderno, o que tornou a segunda metade do século XX como a época do "triunfo" da democracia sobre os demais regimes totalitários, tais como o fascismo e o nazismo. 
Dahl (2001, p.58) apontou vários motivos que demonstraram ser a democracia "a melhor maneira de governar um estado", ao justificar que sua superioridade diante dos outros regimes se dá em virtude de proporcionar as "consequências desejáveis" para uma sociedade, isto é: "evita a tirania, garante a seus cidadãos uma série de direitos fundamentais que os sistemas totalitários não concedem e não podem conceder, garante uma liberdade pessoal mais ampla do que qualquer alternativa viável a ela, ajuda as pessoas a protegerem seus próprios interesses fundamentais", dentre outros.

O propósito do Estado Democrático, em princípio, tem como característica a constituição de um Estado que promova a participação cidadã ativa de seus integrantes, no qual as escolhas e decisões são tomadas para o bem da coletividade, permitindo um desenvolvimento humano que valorize as potencialidades individuais e coletivas, a partir de ideais de liberdade ampla de escolha dos próprios planos de vida, e de igualdade de oportunidade para todos, como consequências também de ampla participação popular na vida pública, contribuindo para a aproximação do aparato estatal das necessidades sociais.

A Constituição Federal vigente define, em seu art. $1^{\circ}$, que a República Federativa do Brasil é um Estado Democrático de Direito, caracterizando-se, principalmente, por se pautar na garantia à liberdade, igualdade e soberania do seu povo, além da sujeição do Estado ao direito, pois, segundo Jesus (2011, p.54), como "instrumental regulado e autorizado pela ordem jurídica".

Nesse contexto, Dallari (1989, p.128) entende como elementos fundamentais na construção do Estado "a supremacia da vontade popular, a preservação da liberdade e a igualdade de direitos", unidos ao princípio da legalidade que se subordina à Constituição. Daí se entender que a legalidade democrática não se detem apenas em seu aspecto formal, pois sua materialidade dever ser instrumento de transformação social (JESUS, 2011, p.55).

Assim, a força normativa-político da Constituição anima as ações do Estado Democrático a garantir a supremacia da pessoa humana e de sua coletividade contra ingerências de poderes absolutos, quer de fonte pública ou privada, que causem menoscabo, violação ou supressão de direitos essenciais para garantir uma existência digna para todos.

Dessa forma, o tema segurança pública tornou-se, nos últimos tempos, um dos mais abordados por toda a sociedade e pelas campanhas políticas, de forma que, ideias para implementá-la eficazmente surgem de todos os setores, e são emitidas tanto por estudiosos quanto por leigos, dando-se em virtude de grande indignação decorrente daquilo que 
presenciam ou do que já sofreram devido às falhas dos órgãos tidos como responsáveis pela garantia da ordem e da segurança públicas.

Insistentemente, as discussões sobre segurança pública giram em torno das atividades policiais voltadas para a manutenção da ordem pública, da incolumidade das pessoas e do patrimônio; valores que, quando agredidos, refletem um desequilíbrio da própria ordem pública.

O entendimento atual conduz à necessidade de uma perspectiva mais apurada da visão sobre segurança pública, de modo que Corrêa (2000, p.9) chama atenção para o fato de que a "a segurança pública se tornou um assunto sério demais para ser abandonado nas mãos da polícia”, e nem ficar adstrita ao comando exclusivo das respectivas secretarias de segurança, pois, como afirma Câmara (2002, p.12):

\footnotetext{
A complexidade da segurança pública não é compreendida pela maioria da população, que acredita tratar-se de assunto de polícia. Essa postura reflete nas autoridades e as consequências dessa desinteligência estão aí, à vista de todos. A perplexidade, aos poucos, vai tomando conta, pois a violência e a criminalidade crescem e as medidas adotadas vêm se mostrando ineficazes.
}

Pode-se inferir que esta miopia é fomentada também pela própria Constituição que, no seu Capítulo III, ao tratar da Segurança Pública, no art. 144, dispõe que:

\footnotetext{
A segurança pública, dever do Estado, direito e responsabilidade de todos. É exercida para a preservação da ordem pública e da incolumidade das pessoas e do patrimônio, através dos seguintes órgãos:

$[\ldots]$

$\mathrm{V}$ policias militares e corpos de bombeiros militares. (grifo nosso) (BRASIL, 2014).
}

Desse modo, informa a Constituição que a segurança pública é direito e responsabilidade de todos, porém, ao atribuir a sua execução, no sentido de manter a ordem pública, a diversas polícias - entre elas, a miliar - reforça o uso legal da força que tais instituições possuem, advindo do próprio poder de polícia do estado.

No entanto, no Estado Democrático de Direito, o entendimento é de que ordem pública exige muito mais do que atuação policial, ela exige principalmente uma preocupação e cuidado com o indivíduo e a sociedade a partir da garantia e promoção de direitos fundamentais, alicerçados pela valorização da dignidade da pessoa humana e dos princípios de liberdade e igualdade, como diretrizes e balizas da atuação dos agentes públicos.

Nessa perspectiva, quando Silva (2012, p.119) aborda a questão do Estado 
Democrático de Direito, ele o faz se referindo ao Estado que agrega mais valores do que as duas qualificações - democrático e de direito - que o acompanham, englobando uma série de elementos, tais como a dignidade da pessoa humana e a justiça social, de modo a ampliar a concepção legalista do Estado e a participação popular. Dai sua afirmação, de que a Constituição brasileira, em comparação com a portuguesa, ao denotar o Estado brasileiro, o faz de modo mais abrangente, ou seja:

A nossa emprega a expressão mais adequada, cunhada pela doutrina, em que o "democrático" qualifica o Estado, o que irradia os valores da democracia sobre todos os elementos constitutivos do Estado e, pois, também sobre a ordem jurídica. O Direito, então, imantado por esses valores, se enriquece do sentir popular e terá que ajustar-se ao interesse coletivo.

Assim, mesmo que a Constituição considere a segurança pública como expressão da atuação da polícia, isolada de outras instituições, nos dias atuais, não se pode mais admitir tal simplificação, visto ter-se ampliado o conceito de segurança pública de tal forma que não há possibilidades de distanciá-lo dos próprios direitos fundamentais e garantias constitucionais, nem dos demais órgãos que compõem a esfera de atuação do poder público, o que leva ao surgimento de um sistema de ações coordenadas e harmônicas que exigem o empenho de todos os setores do Estado, da União e da sociedade.

\section{POLÍCIA MILITAR EM UMA SOCIEDADE DEMOCRÁTICA E LIVRE}

Por mais de 20 anos, a sociedade brasileira viveu sob a ditadura militar que foi interrompida por um contexto de insatisfação, lutas sociais e acordos políticos-militares, cujo ápice inicial se deu com a promulgação da Constituição de 1988. No regime anterior, a segurança era voltada à garantia do Estado contra o inimigo externo - garantir a soberania - e interno - garantir a ordem política instituída, devidamente pautado nas normas da Constituição de 1967 e Emenda Constitucional 1, de 1969, onde a competência para legislar sobre as polícias militares era da União, deixando essas instituições a cargo das Forças Armadas.

Desse modo, como atesta Jesus (2011, p.106), a Constituição de 1967 previa em seu art. $13, \S 4^{\circ}$ que:

As polícias militares instituídas para a manutenção da ordem e segurança interna nos Estados, nos Territórios e no Distrito Federal,[...], são consideradas forças auxiliares, reserva do Exército. 
Temos aí, que as polícias não tinham suas atribuições de segurança pública como uma atividade social e sim, como uma atividade empenhada em manter a segurança interna, cuja força e emprego eram impostos contra todos que, de qualquer forma, ameaçassem o regime, assim considerados como inimigos. Foi um período em que:

\begin{abstract}
A ditadura rasgou a Constituição, fechou o Congresso Nacional, acabou com os partidos políticos, sindicatos, entidades estudantis e populares, demitiu servidores, cassou parlamentares, impôs uma censura brutal, instaurou um regime de medo e implantou o terror. Aos que se opuseram, as prisões, o banimento, o exílio, a tortura, o desaparecimento e a morte (RIO GRANDE DO SUL).
\end{abstract}

Com a finalidade de abater o inimigo e com respaldo constitucional da época, as polícias militares eram comandadas por oficiais do exército que delas se utilizavam para perseguir, torturar e até mesmo matar pessoas com o pretexto de estarem protegendo a segurança nacional.

Desta forma, a influência do regime militar sobre a segurança pública no Brasil é marcante, de tal forma que, mesmo após o advento da Carta Constitucional vigente, traços do antigo regime ainda perduram. A título de exemplos, no Estado do Maranhão, a Polícia Militar foi comandada por oficiais do Exército até o ano 1995, e nos dias atuais ainda utiliza os regulamentos do Exército; a Polícia Militar do Rio de Janeiro teve como secretário de Segurança Pública o General de Exército Newton Cerqueira, no período de 1995 a 1998; e o General de Exército José Siqueira foi o Secretário no período de 1999 a 2000, considerando ainda, que toda a cúpula da Polícia Militar do Rio era comandada por coronéis do Exército (SOARES, 2000, p.168).

Como referido anteriormente, a própria Constituição de 1988 tratou a Segurança Pública como sendo a própria polícia, conforme artigo 144, em que pese o enunciado de ser dever do Estado, direito e responsabilidade de todos da sociedade, a Carta isola a Polícia Militar de outros órgãos do Poder Público e lhe incumbe a "[...] polícia ostensiva e a preservação da ordem pública [...]”, nos termos do $\S 5^{\circ}$, do mesmo artigo (BRASIL, 2018).

Nesse contexto, a Polícia Militar é transportada do regime de exceção para o regime democrático sem qualquer preocupação quanto ao reordenamento de suas estruturas, finalidades e diretrizes, continuando a atuar nas ruas com a visão centrada no combate ao crime e não na prestação de serviço público.

Uma das raízes da violência praticada pela polícia vem do seu entendimento de que o crime tem que ser combatido, e desta forma o combate, como afirma Souza Neto (2011):

É utilizado pelas polícias sob uma concepção bélica, onde criminosos são inimigos internos. As favelas são territórios hostis que precisam ser ocupados através da 
utilização do poder militar. A polícia de segurança é formulada como estratégia de guerra, onde medidas excepcionais se justificam e assim, instaura-se uma política de segurança emergencial.

Agindo sempre sobre o princípio do combate, e com todo seu recente histórico e influência ditatorial, as polícias militares são flagradas, constantemente, cometendo atos violentos e de profundo desrespeito aos direitos humanos que estão legitimados e protegidos na Constituição Federal, tidos como direitos e garantias fundamentais. Visão que difere sobre o conceito contemporâneo de segurança, a partir da perspectiva de serviço público, como dispõe Souza Neto (2011):

[...] a ser prestado pelo Estado. O cidadão é o destinatário desse serviço. Não há mais inimigo a combater, mas cidadão a servir [...] A polícia democrática, não discrimina, não faz distinções arbitrárias: trata os barracos nas favelas como domicílios invioláveis; respeita os direitos individuais, independentemente de classe, etnia e orientação sexual; não só se atém aos limites inerentes ao Estado democrático de direito, como entende que seu principal papel é promovê-lo.

Nesse contexto, o informe 2017/18 da Anistia Internacional, ao abordar sobre a segurança pública no Brasil, confirma que suas unidades federativas adotam práticas policiais repressivas e discriminatórias para o enfrentamento de delitos, momento em que "as Forças Armadas foram cada vez mais designadas a cumprir funções policiais e de manutenção da ordem pública”, e que “[...] As políticas de segurança pública continuaram a se basear em intervenções policiais altamente militarizadas, motivadas principalmente pela chamada política de guerra às drogas” (ANISTIA INTERNACIONAL, 2017/18, p.89).

No mesmo sentido, estatísticas do Fórum Brasileiro de Segurança Pública mostram que das intervenções policiais resultaram 3.320 mortes e ao final de seu relatório chama a atenção para o “ [...] descontrole das polícias e a indução de um modelo belicista que não se coaduna com o Estado Democrático de Direito e com a garantia dos direitos de cidadania pelo Estado" (ANUÁRIO DO FÓRUM BRASILEIRO DE SEGURANÇA PÚBLICA - Atlas da Violência 2017, p. 14)

A nova era democrática trouxe uma concepção de serviço público que as polícias militares têm grande dificuldade de perceber e acolher, e que gera também motivos para a prática de violência por seus integrantes. Entende-se ainda, que a violência policial possui certa conivência com a ordem judicial, visto que, como atesta Mesquita Neto (2011) "os policiais estão autorizados a usar a força física contra outra pessoa no cumprimento do dever legal". Este argumento de "status legal entre os policias e os não-policiais" é quase sempre utilizado nos processos em que são acusados de praticar violência. 
Assim, entende Mesquita Neto (2011) que, do ponto de vista jurídico:

[...] são considerados atos de violência apenas aqueles em que os policiais usam a força física contra outra pessoa de forma ilegal. Isso acontece quando o policial usa a força física não relacionada com o cumprimento do dever legal.

No Brasil há um grande abismo entre o que é previsto na lei, especialmente na Constituição Federal quanto aos direitos fundamentais, e a realidade do que realmente é cumprido. Daí afirmar Pinheiro (1997, p.43) apropriadamente que "os direitos à vida, à liberdade e à integridade pessoal foram reconhecidos e a tortura e a discriminação racial são considerados crime. No entanto, apesar do reconhecimento formal desses direitos, a violência oficial continua".

Com raízes ainda no passado escravocrata do Brasil, na realidade fática do dia a dia, ainda se fazem fortes distinções em relação a cor da pele e a condição econômica das pessoas. Desse modo, ao apontar a condição assimétrica da divisão de classes na sociedade brasileira, Carvalho (2001, p.215-216) a relaciona com o Estado e com a Polícia, como segue:

A "primeira classe", os privilegiados, os doutores, que estão acima da lei, que sempre conseguem defender seus interesses pelo poder do dinheiro e do prestígio social. Os "doutores" são invariavelmente brancos, ricos bem vestidos, com formação universitária. São empresários, banqueiros, grandes proprietários rurais e urbanos. Frequentemente, mantêm vínculos importantes nos negócios, no governo e no judiciário. Esses vínculos permitem que a lei só funcione em seu benefício.

Em continuação, o autor descreve o que ele chama de "segunda classe":

Estão sujeitos aos rigores e benefícios da lei. São a classe média modesta, os trabalhadores assalariados com carteira de trabalho assinada, os pequenos funcionários, os pequenos proprietários urbanos e rurais. [...] Frequentemente ficam a mercê da polícia e de outros agentes da lei que definem na prática que direitos serão ou não respeitados.

E conclui sua descrição como segue:

Finalmente, há os "elementos" do jargão policial, cidadãos de terceira classe. É a grande população marginal das grandes cidades, trabalhadores urbanos, rurais sem carteira assinada, posseiros, empregadas domésticas, biscateiros, camelôs, menores abandonados, mendigos. São quase invariavelmente pardos, negros, analfabetos, ou com educação fundamental incompleta.[...] $\mathrm{Na}$ prática, ignoram seus direitos civis ou os têm sistematicamente desrespeitados por outros cidadãos, pelo governo, pela polícia. Não se sentem protegidos pela sociedade e pelas leis.

Ainda, corroborando com tal afirmação, Pinheiro (1997, p.44) aponta que:

Hoje em dia, o principal alvo da arbitrariedade policial são os mais vulneráveis e indefesos da sociedade brasileira: o pobre, o trabalhador rural e sindicalistas, grupos minoritários, crianças e adolescentes abandonados, muitos vivendo nas ruas. Muita dessa violência é alimentada por uma discriminação enraizada na sociedade contra os pobres e as minorias raciais, que são em sua maioria vítima de homicídio. 
Assim, este quadro está profundamente relacionado com a violência social que impera no Brasil que decorre da ausência de adequada intervenção estatal em diversos setores, condição agudizada pelas políticas neoliberais que aprofundam diuturnamente a desigualdade, a exclusão e a injustiça sociais, condenando milhões a viver na marginalidade de suas dignidades humanas.

Alinha-se a esse quadro, o entendimento de que a violência é reproduzida verticalmente na cadeia hierárquica da riqueza, isto é, pela difusão de uma cultura autoritária dos economicamente privilegiados - elites - contra "os outros", há também a reprodução desta condição de violência entre os mais pobres. Afirma ainda Pinheiro (1997, p.44) que:

O Brasil, [...] é uma sociedade que se baseia na exclusão, uma democracia sem cidadania [...]. A polícia tende a agir como guarda de fronteira do rico contra os pobres e a violência policial permanece fechada na impunidade porque ela é exercida contra essas classes perigosas e raramente afeta as vidas dos bem-de-vida.

A vontade estatal se impõe pela força do direito - e da polícia - que, como visto, em um Estado Democrático de Direito, deve privilegiar a garantia e o fomento do bem-estar coletivo. No Brasil, entretanto, tais forças são utilizadas para proteger interesses de grupos economicamente já privilegiados, em detrimento dos menos favorecidos, surgindo daí também o mau uso da polícia pelo próprio Estado.

Nessa perspectiva, muitas são as concepções e atribuições que se confundem no campo da segurança pública, mas todas se baseiam na ideia da simples prevenção e repressão da violência, atividade realizada pelos órgãos de segurança pública definidos na Constituição Federal vigente. Daí afirmar Palmieri (2003, p.13) que:

As respostas que propugnam a ordem nas ruas como único objetivo não somente tendem à restrição dos direitos cidadãos, como ao simplificar a complexidade da questão - são ineficazes e até irresponsáveis, uma vez que "iludem" os cidadãos com respostas fáceis e rápidas que, em realidade, somente podem provocar mais violência, riscos e insegurança.

Neste contexto, as formas intuitivas de tratar a segurança pública tem sido configuradas como verdadeiros desastres para o povo brasileiro, uma vez que a gestão de Segurança Pública, um tema complexo, tem que ser feita com conhecimento científico (BALESTRETI, 2010, p.63). Desse modo, tem-se como essencial a distinção entre segurança pública e polícia, e entender qual a finalidade precípua do Estado, tal como atesta Câmara (2002, p.141):

Primeiramente, precisamos distinguir segurança pública e polícia. Não são sinônimos, como muitos ainda acreditam. A polícia integra, é uma parte, mas não exaure as ações e missões afetas à segurança pública. $\mathrm{O}$ passo seguinte é relembrar 
que o Estado, do qual as duas fazem parte, foi criado pelo cidadão para viabilizar sua vida em sociedade. Assim, a polícia está (ou deve estar) a serviço dela. A arma dada ao policial é para proteger o cidadão e não para ser usada contra ele.

Como ressaltado anteriormente, a Constituição Federal dispõe que "segurança pública é dever do Estado e responsabilidade de todos", atentando-se ainda para o fato de que a expressão "segurança" está presente na Carta em vários dispositivos, a começar pelo próprio Preâmbulo, que dá o norteamento, no sentido amplo do termo, de que o Estado deve sempre promover ações para o alcance do bem estar dos seus integrantes; além de que, a iniciativa da sociedade como participante na promoção da segurança pública depende de políticas estatais que promovam essa conscientização e que permitam uma participação de forma mais direta e segura, sem retaliações do próprio Estado.

Desse modo, a segurança pública, em especial, a polícia, confronta-se com as consequências da ausência de intervenção do Estado em outros setores, tais como: educação, saúde, moradia, justiça; uma vez que, como afirma Chaves (2006, p.14): “Onde não há emprego, saúde, educação, segurança, transporte, saneamento básico, lazer, honestidade e dignidade, há violência".

O alarmante número de ocorrências envolvendo as secretarias de segurança dos Estados em atos de violência induziu à necessária participação mais ativa da União junto ao sistema de segurança pública, por entender que apenas desta forma seria possível maior valorização das regras constitucionais vigentes.

Com a participação do Governo Federal através da Secretaria Nacional de Segurança Pública (SENASP), surgiram políticas voltadas para a humanização e valorização do profissional de segurança pública e para o incentivo de maior participação da sociedade.

Destacam-se, dentre elas, a criação do Programa Nacional de Segurança Pública e Cidadania - PRONASCI, que tem o papel de implementar uma política de respeito aos Direitos Humanos na atuação policial, agindo com a participação da sociedade, para, no dizer de Mesquita Neto (2011), “[...] principalmente, monitorar [...], avaliar resultados, colaborar para promover e consolidar avanços na redução do crime e da violência e promoção da segurança pública”.

Também merece destaque a implantação da polícia comunitária, uma experiência importada de outros países, onde apresentam excelentes resultados no combate à criminalidade e à violência policial, tais como, "na Europa Ocidental, na América do Norte, na Austrália e Nova Zelândia, e no Oriente [...]” (SKOLNICK, 2006, p.15). 
Muitas instituições militares ainda preocupadas com a formação e capacitação de seus integrantes acabaram por levar o curso de formação dos seus oficiais para dentro da Universidade. O pioneirismo desta modalidade de preparo do policial ocorreu no Maranhão, no ano de 2003, quando os candidatos ao Curso de Formação de Oficiais (CFO) daquele ano, se submeteram ao vestibular da Universidade Estadual do Maranhão (UEMA) onde, quando formados, saem com Bacharelado em Segurança Pública.

Há também, serviços de prevenção como o Programa Educacional de Resistência às Drogas e à Violência (PROERD), onde crianças, jovens e adultos recebem cursos, ministrados por policiais militares com o objetivo de envolver a polícia, a escola, a família e a comunidade na problemática das drogas e da violência, desenvolvendo um espírito de solidariedade, de cidadania e de comunidade nas escolas.

Outra iniciativa importante, no campo da conscientização e formação dos agentes de polícia no sentido de compreender seu papel de colaboração para a harmonia social e a implementação dos direitos humanos fundamentais, deu-se com a criação do Programa Nacional de Direitos Humanos (PNDH-3), por meio do Decreto n. 7.037, de 21 de dezembro de 2009, que contou com a colaboração de diversos segmentos da sociedade e militantes dos direitos humanos no Brasil.

Assim, o PNDH-3 enfatizou, em seu Eixo Orientador IV, a Segurança Pública, o Acesso à Justiça e o Combate à Violência, cujas propostas se encontram em harmonia com o processo de democratização do país e de suas instituições, que pedem urgentemente a reforma do modelo de polícia que ainda traz em si os resquícios das orientações do período ditatorial, atestando ainda, a importância da participação social nesse processo de renovação (BRASIL, 2010).

Assim, não é de hoje que esses aspectos da formação da Polícia Militar têm chamado atenção, tanto das autoridades públicas, como da sociedade em geral, especialmente nos momentos de crise institucional. Além disso, a visão do "inimigo interno", principalmente os de condições mais desfavoráveis e historicamente excluídos, por sua cor ou por sua condição econômica, têm reflexos fortes na política de encarceramento e no aumento das vítimas pela violência policial.

Pode-se aferir a relevância dessas ações na segurança pública, a partir da fala de Soares (2000, p.41), ao relatar sua experiência como Secretário de Segurança Pública do Estado do Rio de Janeiro, quando conclui que somente "um tratamento transformador e 
radicalmente democrático da segurança pública, particularmente do 'comportamento do policial', é decisivo para a democratização efetiva e completa da sociedade brasileira".

Na perspectiva aqui apresentada, entende-se que a segurança pública e a ação da polícia militar vão além de questões de garantia patrimonial e incolumidade física, pois caracterizam, quando adequadamente fundamentadas, um autêntico Estado Democrático de Direito cuja finalidade primordial é a concretização dos direitos humanos fundamentais em igual liberdade de acesso aos bens necessários para promoção da dignidade de vida, tanto na dimensão individual quanto na coletiva.

\section{CONCLUSÃO}

O período de transição do regime ditatorial de 1864 a 1985 para o processo de redemocratização contemporânea foi marcado por vitórias e por inconsistências, isto é, em que pese a nova ordem política e jurídica que estava prestes a se instaurar com a Constituição de 1988, características do período anterior permaneceram no seio das instituições do poder público em todas as suas esferas.

Uma das marcas da ditadura têm se sobressaído ultimamente, em especial quando a participação popular é chamada a criticar posicionamentos autoritários do governo vigente ou passa a exigir de maneira mais contundente seus direitos.

Após este estudo, constatou-se que a segurança pública e a Polícia Militar, no recente processo de democratização do Brasil, surgem entre os temas principais a serem encarados e resolvidos pelo Estado na condição de serviços públicos a serem prestados com mais qualidade ao cidadão. No entanto, ficou demonstrado, que ainda não se consideram o fato de que segurança pública está intimamente comprometida com os direitos fundamentais do cidadão, visto que a agressão, a tais direitos, se inicia com o próprio descaso do Estado Brasileiro, que com sua política de exclusão contribui drasticamente para o quadro de pobreza e criminalidade do país.

Conclui-se ainda que a Polícia Militar apresenta na sua formação influências das práticas de violência que por muitos anos se fez utilizar, em virtude de sua subordinação às Forças Armadas durante o Estado de Exceção em que os direitos à vida, liberdade e igualdade, dentre outros, não eram respeitados. No entanto, este órgão tem procurado ao 
longo dos anos se adaptar às exigências de uma sociedade democrática e livre que precisa dos serviços da polícia ao seu favor e não contra.

Constatou-se, ainda, que a violência no Brasil encontra argumentos de defesa até mesmo no sistema jurídico mediante o conceito legal do uso de força, efetivando, muitas vezes, a implantação de uma política de exclusão fomentada pelo Estado, que muito pouco se preocupa na efetivação dos direito fundamentais e se utiliza dos seus órgãos policiais de forma repressiva para, ilicitamente, restringir direitos.

O presente trabalho conclui também pela complexidade que envolve a Segurança Pública e as causas de violência praticadas pela Polícia Militar, o que exigiu uma participação mais efetiva do Governo Federal, que se apresentou com a criação de órgão Federal com o objetivo de orientar e padronizar a atuação das Secretarias de Segurança Estaduais, inclusive com implementação de verbas federais nas ações voltadas para a segurança da sociedade.

Percebe-se também a importância da efetiva implementação dos Programas Nacionais de Direitos Humanos, especialmente no que se refere à segurança pública e o papel das polícias militares, pois é por meio da formação e da educação que se pode contribuir para que uma cultura beligerante e de imposição do medo, possa se transmudar em outra que tenha como finalidade a difusão da solidariedade e do respeito ao outro.

Enfim, conclui-se que a Polícia Militar ainda é de grande importância para a sociedade, e sua atuação tem que estar perfeitamente ordenada no sentido de respeitar os direitos fundamentais individuais e sociais, como responsabilidade primordial do sistema de Segurança Pública que deve ser entendido como uma estrutura que envolve todos os segmentos do poder público e da sociedade. Para que, desta maneira, seja possível combater a violência de todas as formas em que se apresenta, proporcionando assim, maior legitimidade ao Estado Democrático de Direito.

\section{REFERÊNCIAS}

ANISTIA INTERNACIONAL. Informe 2017/18: O Estado dos Direitos Humanos no Mundo. Amnesty Internacional Ltd. Londres: Anistia Internacional 2017/18. Disponível em:< https://anistia.org.br/wp-content/uploads/2018/02/informe2017-18-online1.pdf> Acesso em 05 abril de 2018.

ANUÁRIO DO FÓRUM BRASILEIRO DE SEGURANÇA PÚBLICA. Atlas da Violência 2017. Rio de Janeiro, 2017. IPEA: Fórum Brasileiro de Segurança Pública. Disponível em: <http://www.forumseguranca.org.br/wp-content/uploads/2017/06/FBSP_atlas_da_violencia_ 20 17_apresentacao.pdf >. Acesso em 05 de abril de 2018. 
BALESTRERI, Ricardo. Um novo Paradigma de Segurança Pública. In: COSTA, Ivone Freire; BALESTRERI, Ricardo Brisolla (orgs). Segurança Pública no Brasil: um campo de desafios. Salvador: Edufba, 2010.

BRASIL. Programa Nacional de Direitos Humanos (PNDH-3). Secretaria Especial de Direitos Humanos da Presidência da República. Brasília: SEDH/PR, 2010. Disponível em: $<$ http://www.sdh.gov.br/assuntos/direito-para-todos/programas/pdfs/programa-nacional-dedireitos-humanos-pndh-3>. Acesso em 15.fev.2018.

BRASIL. Código civil, código de processo civil, código comercial, constituição federal, legislação federal, legislação civil, processual civil e empresarial. Obra coletiva de autoria da Editora Revista dos Tribunais. Organização de Yussef Said Cahali. 16 ed. rev., ampl. e atual. São Paulo: Editora Revista dos Tribunais, 2014.

CÂMARA, Paulo Sette. Reflexões sobre segurança pública. Belém-PA, Unama, 2002.

CARVALHO, José Murilo. Cidadania no Brasil - O longo caminho. Rio de Janeiro, Civilização Brasileira, 2001. CARVALHO, José Murilo. Cidadania no Brasil - O longo caminho. Rio de Janeiro, Civilização Brasileira, 2001.

CHAVES, Geraldo José. Segurança pública: o que pode ser feito. Brasília-DF: Envelopel. 2006.

CORRÊA, Marcos Sá. Prefácio. In: SOARES, Luiz Eduardo. Meu casaco de general quinhentos dias no front da segurança pública do Rio de Janeiro. São Paulo: Companhia das Letras, 2000.

DAHL, Robert A. Sobre a Democracia. Tradução de Beatriz Sidou. Brasília: Editora Universidade de Brasília, 2001.

DALLARI, Dalmo de Abreu. Elementos de teoria geral do Estado. São Paulo: Saraiva, 1989.

JESUS, José Lauri Bueno de. Polícia Militar e Direitos Humanos: Segurança Pública, Brigada Militar e os Direitos Humanos no Estado Democrático de Direito. Curitiba-PA, Juruá Editora, 2011.

MESQUITA NETO, Paulo de. Violência policial no Brasil: abordagens teóricas e práticas de controle. Disponível em: < http://www.comunidadesegura.org.br/files/violenciapollcialno brasilabordagensteoricasepraticasdecontrolepaulomesquitaneto.pdf> Acesso: 20.jan. 2018.

PALMIERI, Gustavo et al. Segurança cidadã e polícia na democracia. Rio de Janeiro, Konrad Adenaur Stiftung, 2003.

RIO GRANDE DO SUL. Relatório Azul 1996. Comissão de Cidadania e Direitos Humanos da Assembleia Legislativa do Estado do Rio Grande do Sul 1997. Disponível em: <www.al.rs.gov.br/download/CCDH/RelAzul/relatorioazul-96.pdf>. Acesso: 15.fev.2018. 
SKOLNICK. Jerome H. et al. Policiamento Comunitário - questões e práticas através do mundo. São Paulo: Universidade de São Paulo, 2006.

SILVA, José Afonso da. Curso de direito constitucional positivo. 35 ed rev e atual. São Paulo: Editora Malheiros, 2012.

SOARES, Luiz Eduardo. Meu casaco de general - quinhentos dias no front da segurança pública do Rio de Janeiro. São Paulo: Companhia das Letras, 2000.

SOUZA NETO, Cláudio Pereira de. A Segurança Pública na Constituição Federal de 1988: Conceituação constitucionalmente adequada, competências federativas e órgãos de execução das políticas. Disponível em:

<http://www.direitopublico.com.br/redirect_pdf.php?id=233> Acesso: 12.jan. 2018. 